\title{
Joining of Silicon Carbide and Molybdenum with Vanadium Foil
}

\author{
Yoshiro Ito and Tomomi Jinbo ${ }^{\dagger}$ \\ Department of Mechanical Engineering, Nagaoka University of Technology, \\ 1603-1, Kamitomioka, Nagaoka, Niigata 940-21, Japan
}

\begin{abstract}
A joining pair of silicon carbide and molybdenum was fabricated using vanadium foil as an insert material. The optimum fabricating conditions are bonding temperature of $1198 \mathrm{~K}$, bonding pressure of $30 \mathrm{MPa}$ and bonding time of $10.8 \mathrm{ks}$. The joint had high shear strength levels of $150 \mathrm{MPa}$ at room temperature and of $52 \mathrm{MPa}$ at $973 \mathrm{~K}$. At the interface of silicon carbide and vanadium, a layer of vanadium silicide $\mathrm{V}_{3} \mathrm{Si}$ was formed.
\end{abstract}

(Received May 20, 1993)

Keywords: joining pair, silicon carbide, molybdenum, vanadium foil, shear strength, vanadium silicide

\section{Introduction}

Silicon carbide $(\mathrm{SiC})$ is one of the fine ceramics which find application in a high temperature environment. Thus a joint of $\mathrm{SiC}$ with a metal should have high mechanical strength at elevated temperatures. Most of the joining methods developed so far have used soft metals and/or their alloys as insert materials or brazes. These soft metals have a low melting point in general and, therefore, joints thus formed have poor mechanical strength at high temperature $\mathrm{e}^{(1)(2)}$.

We have developed a bonding method of silicon nitride to molybdenum with a vanadium interlayer ${ }^{(3)}$. Vanadium has a high melting point and thus the joint has high shear strength at about $1000 \mathrm{~K}$. At the interface of silicon nitride and vanadium, a layer of a vanadium silicide $\mathrm{V}_{3} \mathrm{Si}$ was formed.

We have applied this method to make a SiC-metal joint and obtained a sound joint which has high mechanical strength at elevated temperatures.

\section{Experimental}

$\mathrm{SiC}$ was supplied from Asahi Glass Co. and contained both an aluminum (Al) compound and a magnesium $(\mathrm{Mg})$ compound as sintering additives. It was supplied as rods of $12 \mathrm{~mm}$ diameter and was cut into disks of $5 \mathrm{~mm}$ thickness. Both surfaces of the disk were mechanically polished to a surface roughness of $3 \mu \mathrm{m}$.

Molybdenum (Mo) was a disk $5 \mathrm{~mm}$ thick and $8 \mathrm{~mm}$ in diameter and its surfaces were polished. Vanadium (V) foil of $25 \mu \mathrm{m}$ thick was used as an insert material. The purity of Mo and V was $99.95 \%$.

The $\mathrm{V}$ foil was inserted between $\mathrm{SiC}$ and Mo disks and this assembly was bonded in a vacuum furnace equipped with a hand made mechanical press. When the furnace temperature reached to designed values, the mechanical

$\dagger$ Graduate Student, Nagaoka University of Technology. Present address: Murata Mfg. Co., Ltd., Kyoto, Japan. pressure was applied for a certain bonding time. The strength of the joint was measured by shear test with hand made jigs at room temperature and elevated temperatures. Details of the experimental procedures were the same to the previous paper ${ }^{(3)}$.

\section{Results}

Figure 1 shows the shear strength level of the joined interface at room temperature as a function of bonding pressure at the temperature of $1198 \mathrm{~K}$ and the bonding time of $10.8 \mathrm{ks}$. The strength level reached $130 \mathrm{MPa}$ at bonding pressures higher than $30 \mathrm{MPa}$ and times longer than $10.8 \mathrm{ks}$. With a further increase both in pressure and in time, the increase in the strength level of the joints ceased.

There were small peaks in the load-displacement curves and fracturing in the ceramics occurred at these peaks. The first small peak appeared at almost equal loads and some cracks were observed in the ceramics. The crack started at the upper edge of the metal disk,

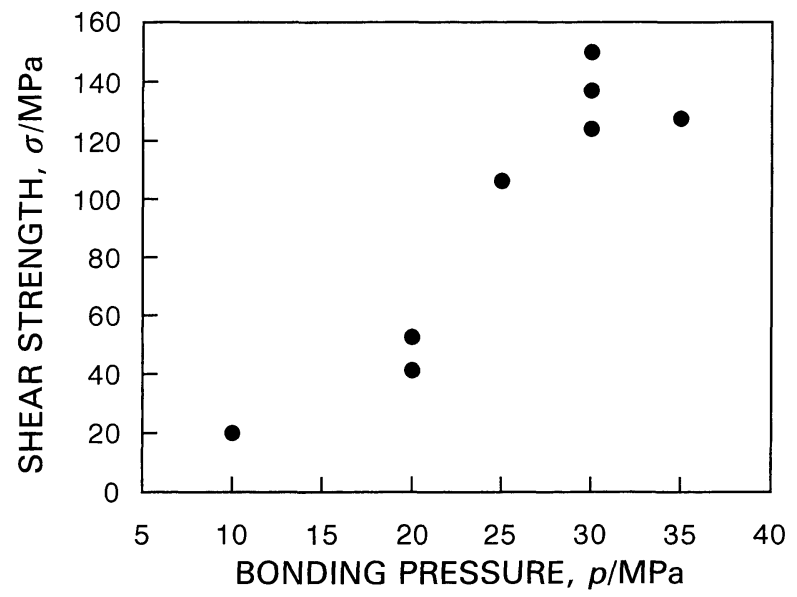

Fig. 1 Effect of bonding pressure on the shear strength of the joint at room temperature at the bonding temperature $1198 \mathrm{~K}$ and the bonding time of $10.8 \mathrm{ks}$. 
which was smaller than the ceramics disk, and extended into the ceramics. This failure was evidently caused by residual thermal stresses concentrated on the boundary of the metal disk. The final fracture was, however, occurred at the ceramics-metal interface and the strength level of the interface was determined.

The influence of fabricating temperature is presented in Fig. 2. The pressure was $30 \mathrm{MPa}$ and the bonding time was $10.8 \mathrm{ks}$. The strength increased with increasing temperature in the region between 1073 and $1198 \mathrm{~K}$. At higher temperatures, it decreased with the increase in temperature and finally no bonding occurred at $1273 \mathrm{~K}$. The strongest joints were obtained at $1198 \mathrm{~K}$; their average interface strength was $125 \mathrm{MPa}$, the maximum and minimum values being 150 and $100 \mathrm{MPa}$, respectively.

The optimum fabricating conditions thus determined are:

Temperature, $1198 \mathrm{~K}$;

Pressure, $30 \mathrm{MPa}$;

Bonding time, $10.8 \mathrm{ks}$.

The pressure and time listed above are the minimum necessary to attain high shear strength. Most of the results described below are for the samples fabricated in these optimum conditions.

Shear strength levels measured at elevated temperatures are shown in Fig. 3. In the high temperature measurement, test jigs used were different from those used at room temperature ${ }^{(3)}$. At high temperatures, the joint fractured at the interface and no small peaks appeared at a low load. The shear strength of the interface was $55 \mathrm{MPa}$ at $673 \mathrm{~K}$ and $52 \mathrm{MPa}$ at $973 \mathrm{~K}$. The strength level seemed to be constant at the test temperatures between 673 and $973 \mathrm{~K}$.

A SEM observation of the joined part revealed that the interface between the molybdenum and vanadium was a smooth and clear single boundary without any cracks or voids. Between $\mathrm{V}$ and $\mathrm{SiC}$, a new layer about $1.2 \mu \mathrm{m}$ thick was formed. Both boundaries of the layer were smooth and free of voids or cracks.

The distribution of several elements across the V-SiC interface was measured by EPMA. The distribution profiles of $\mathrm{V}$ and silicon (Si) showed narrow plateaus coinciding with each other in the intermediate layer. Thus the compound of Si and V should form the layer. The profiles of other elements such as Al did not show such plateaus.

X-ray diffraction patterns from the fractured surfaces showed the peaks originating from a vanadium silicide $\mathrm{V}_{3} \mathrm{Si}$ in addition to those of $\mathrm{V}$ or $\mathrm{SiC}$. The peaks of $\mathrm{V}$ were absent in the diffraction patterns from the ceramics side or vice versa, but the peaks from $\mathrm{V}_{3} \mathrm{Si}$ were observed on both sides. No additional diffraction peak existed which might be assigned to other vanadium silicides. Thus, the joint fractured in the reaction layer which composed of $\mathrm{V}_{3} \mathrm{Si}$ located between $\mathrm{V}$ and $\mathrm{SiC}$. The $\mathrm{X}$-ray patterns from the unjoined pairs treated at $1373 \mathrm{~K}$ showed strong $\mathrm{V}_{3} \mathrm{Si}$ peaks with additional peaks of $\mathrm{V}_{5} \mathrm{Si}_{3}$. None of the peaks could be assigned to vanadium carbide or graphite.

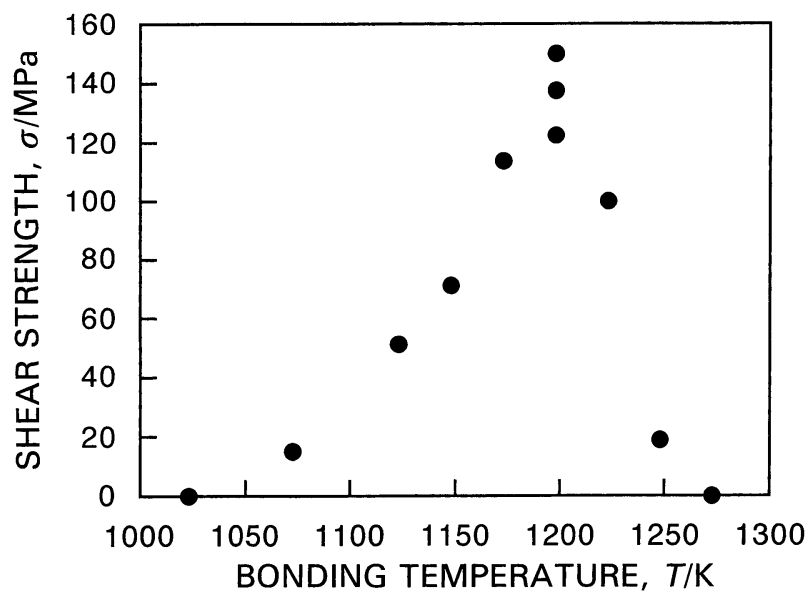

Fig. 2 Influence of bonding temperature on the shear strength of the joint measured at room temperature. The bonding pressure was 30 $\mathrm{MPa}$ and bonding time was $10.8 \mathrm{ks}$.

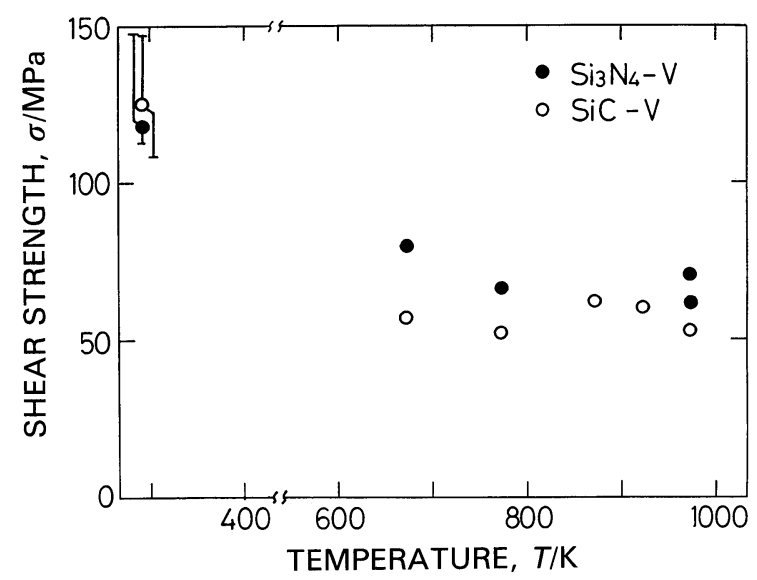

Fig. 3 Shear strength levels of the joints measured at elevated temperatures. Joints were fabricated under the optimum conditions. The results for $\mathrm{Si}_{3} \mathrm{~N}_{4}-\mathrm{V}^{(3)}$ are reproduced for comparison.

\section{Discussion}

A study on high temperature reaction between $\mathrm{SiC}$ and platinum $(\mathrm{Pt})$ was reported ${ }^{(4)}$. $\mathrm{SiC}$ was decomposed to form metal silicides at 1173 and $1273 \mathrm{~K}$, where the Gibbs free energy of $\mathrm{SiC}$ decomposition was expected to be highly positive. In this system, however, alternating layers of $\mathrm{Pt}_{3} \mathrm{Si}$ and $\mathrm{Pt}_{2} \mathrm{Si}$ which contained carbon particles were formed in the reaction zone. Interfacial melting occurred in the system. These results were quite different from our results on the $\mathrm{SiC}-\mathrm{V}$ system in which some reaction should occur through solid state reactions. It would be probable that free carbon was formed from the decomposition of $\mathrm{SiC}$ and dispersed in the reaction zones or metals. The free carbon should be very small particles for the SEM observation and X-ray diffraction measurement, which may be the reason why neither carbon (graphite) particle nor vanadium carbide was observed. 
Our results are quite parallel to those at the interface of silicon nitride and vanadium ${ }^{(3)}$. The optimum bonding temperature was, however, lower than that for silicon nitride of $1328 \mathrm{~K}$. The detectable reaction products were silicides of vanadium, $\mathrm{V}_{3} \mathrm{Si}$ and $\mathrm{V}_{5} \mathrm{Si}_{3}$, and not carbides or nitrides of $\mathrm{V}$. The reaction phase formed at lower temperature is $\mathrm{V}_{3} \mathrm{Si}$ and additional formation of $\mathrm{V}_{5} \mathrm{Si}_{3}$ at higher temperatures seems to weaken the strength of the joint. These results suggest that the reaction between $\mathrm{Si}$ and $\mathrm{V}$ is important in these systems so long as the decomposition of $\mathrm{SiC}_{\text {or }} \mathrm{Si}_{3} \mathrm{~N}_{4}$ is allowed to occur. The temperature dependences of the shear strength levels for both $\mathrm{SiC}-\mathrm{V}$ and $\mathrm{Si}_{3} \mathrm{~N}_{4}-\mathrm{V}$ are quite parallel as indicated in Fig. 3 in which the results for $\mathrm{Si}_{3} \mathrm{~N}_{4}-\mathrm{V}$ are reproduced. This suggests that the high temperature strength of these joints is determined by the strength of the reaction layer.

The first phase to be formed in $\mathrm{Si}$ and $\mathrm{V}$ reaction is $\mathrm{V}_{2} \mathrm{Si}^{(5)}$. The free energy change of formation of vanadium silicides at $1327 \mathrm{~K}$ was favorable to formation of $\mathrm{V}_{5} \mathrm{Si}_{3}{ }^{(6)}$. Our X-ray diffraction measurements, however, indicated that $\mathrm{V}_{3} \mathrm{Si}$ was formed at first and then $\mathrm{V}_{5} \mathrm{Si}_{3}$ was formed at higher temperatures. The temperature range in which the $\mathrm{V}_{3} \mathrm{Si}$ formed for $\mathrm{SiC}-\mathrm{V}$ bonded pair was lower and narrower than that for $\mathrm{Si}_{3} \mathrm{~N}_{4}-\mathrm{V}$ bonded pair. These suggest that the thermochemical free energy change is not the principal parameter which controls the interfacial reactions in these systems. A similar deviation from the thermochemical rule was reported in the $\mathrm{Si}-\mathrm{V}$ thin layer reactions ${ }^{(5)(7)(8)}$. A probable reaction controlling factor is the transport properties of reaction species, $\mathrm{V}$ and $\mathrm{Si}$, through the materials and the reaction products layers. To clarify these contributions, however, the concentrations, diffusion coefficients and activities of the reactive species should be known. Unfortunately, we have no such data at hand and studies to obtain the information are highly needed for each combination of ceramics-metal joints.

\section{Acknowledgments}

We are grateful to Asahi Glass Co. for supplying us the silicon carbide sample. We wish to thank Professor M. Kanno for his support and encouragement to our study.

\section{REFERENCES}

(1) G. Elssner and G. Petzow: ISIJ International, 30 (1990), 1011.

(2) K. Suganuma: ibid., 30 (1990), 1046.

(3) Y. Ito, K. Kitamura and M. Kanno: J. Mater. Sci., in press.

(4) T. C. Chou: J. Mater. Sci., 26 (1991), 1412.

(5) K. N. Tu, J. F. Ziegler and C. J. Kircher: Appl. Phys. Lett., 23 (1973), 493.

(6) V. N. Yeremenko, G. M. Lukashenko and V. R. Sidorko: Rev. int. Htes. Temp. et Refract., 12 (1975), 237.

(7) J. W. Mayer and K. N. Tu: J. Vac. Sci. Technol., 11 (1974), 86.

(8) R. J. Schutz and L. R. Testardi: J. Appl. Phys., 50 (1979), 5773. 